\title{
Batismo de fogo e gravador desligado: notas sobre embaraços vividos pelo pesquisador no cotidiano do trabalho de campo
}

\author{
Rosemeire Aparecida Scopinho ${ }^{1}$ e Charles dos Santos ${ }^{2}$ \\ Universidade Federal de São Carlos (São Carlos, SP)
}

Os caminhos e atalhos definidos para lidar com as diferentes situações vivenciadas no fazer cotidiano dos que trabalham com pesquisa social qualitativa nem sempre são declarados e devidamente analisados como componentes intrínsecos ao campo empírico e ao objeto de estudo. Procuramos refletir sobre como certas situações por nós vivenciadas no cotidiano do trabalho científico contribuíram, substancialmente, para a nossa formação tornando possível nos situarmos adequadamente no campo empírico e esclarecermos os nossos objetos de estudo de melhor forma. Organizamos a reflexão em duas seções. A primeira - batismo de fogo - trata dos testes empreendidos pelos pesquisados para aceitar os pesquisadores no campo empírico. A segunda - gravador desligado - trata das formas definidas pelos pesquisados para a participação na pesquisa. A reflexão contribui para a reafirmação dos pressupostos da pesquisa qualitativa, no entanto, não deve ser entendida como regra de manual, mas como parte de uma experiência de trabalho singular vivida por determinados pesquisadores na relação estabelecida com determinados sujeitos em determinados espaços e tempos sociais.

Palavras-chave: Pesquisa Qualitativa, Campo Empírico, Trabalho do Pesquisador.

Baptism of fire and recorder off: notes on embarrassments experienced by the researcher in daily work field

The paths and routes defined to manage different situations experienced in the everyday routine of working with qualitative social research are not usually declared and properly analyzed as intrinsic components to the empirical field and to the object of study. We tried to think about how certain situations experienced by us in daily scientific work routine contributed substantially to our training, to better situate us in empirical field and clarify our objects of study. The reflection was organized in two sections. The first one - baptism of fire - discusses the tests undertaken by people surveyed to accept the researchers in the empirical field. The second one - recorder off - deals with the forms defined by respondents to be part of the research. The reflection contributed to reaffirm assumptions on qualitative research, however, should not be understood as a manual, but as part of a singular work experience lived by certain researchers during their relationships with certain subjects, in certain spaces and social times.

Keywords: Qualitative research, Empirical field, Researcher's work.

\section{Introdução}

$\mathrm{O}$ que aqui chamamos de embaraços vividos pelo pesquisador no cotidiano do trabalho de campo é aquela situação que não está ou raramente está contemplada ou mesmo até contraria o que está prescrito nos manuais de métodos de pesquisa qualitativa. O termo campo, no contexto desse trabalho, é entendido não apenas como lugar específico onde dados são coletados. E sim como campo-tema, um complexo de redes de sentido interconectadas sobre um determinado assunto (Spink, 2003), sendo também campo de produção, espaço social de relações objetivas que podem explicar as formas concretas que assumem as interações que se estabelecem entre os agentes presentes nele (Bourdieu, 2007). Em suma, é local de pesquisa e de produção de conhecimento; é o local de trabalho do pesquisador - trabalhador da ciência - e, como tal, é campo de relações assimétricas de poder em dois sentidos, como explica Bourdieu (1997): 1. porque é o pesquisador quem define, propõe e domina as regras do jogo, embora o pesquisado também seja capaz que fazêlo; e 2. o pesquisador sempre ocupa uma posição hierárquica superior, especialmente no que se

1 Departamento de Psicologia.

2 Programa de Pós-Graduação em Sociologia. 
refere à posse de capital cultural. É no cotidiano do trabalho de campo do cientista social que esses diferentes campos, e as relações assimétricas neles configuradas, se fundem. Cotidiano, para Spink (1991, p. 27, grifos do autor), "não é um vazio de restos aleatoriamente espalhados pelo chão. Ao contrário, é o lugar onde a gente se conhece como gente - comendo, amando, brigando, andando e trabalhando." Porém, mais do que um conjunto de ações diárias e corriqueiras, cotidiano é também reflexo e antecipação da história, como refere Whitaker (2002):

...é no cotidiano que se podem colher os dados da transformação cultural e realizar a observação das práticas culturais - sua desestruturação e reconstrução - e é em meio às práticas culturais e ao trabalho que se tecem as representações que organizam os homens no processo dinâmico em que constroem a História. (p. 45)

Nesses campos, como em tantos outros do mundo do trabalho, algumas situações são vividas, cotidianamente, de maneira embaraçosa, porque a formação teórica e metodológica do pesquisador nem sempre contribui para o entendimento da pesquisa social na perspectiva qualitativa como um processo não linear e sujeito a conflitos, uma vez que eles não são os únicos portadores de expectativas e interesses. Mesmo quando a proposta é a de trabalhar com abordagens metodológicas participativas e obedecendo fielmente aos preceitos éticos, há dificuldade para pensar a pesquisa de campo como uma relação que, embora envolva sujeitos distintos, do ponto de vista ético deve ser, de fato, simétrica e não instrumental; ao contrário, geralmente, a tendência é pensá-la como uma relação unidirecional onde os interesses do pesquisador são mais relevantes ou, simplesmente, como "parte" necessária de um processo que levará à conclusão um projeto de pesquisa. E por mais que a ideia da pesquisa de campo como processo de interação horizontal circule, abstratamente, nos manuais de metodologia, é somente quando, em carne e osso, o pesquisador entra no campo de pesquisa que este fenômeno pode ser, concretamente, percebido. Ali ele tem que se identificar e negociar a entrada na vida do outro, esclarecer propósitos, equalizar interesses e sincronizar agendas. E isto é só o começo porque, no decorrer do processo, intercorrências de diferentes ordens podem ter de ser enfrentadas: ausências e atrasos, desistências, esperas às vezes longas e inúteis, fatos que abalam e até contradizem as certezas teóricas e também situações que exigem mais do que realizar a pesquisa em si e que muito informam sobre a concretude do sujeito que dela participa. Sobretudo, como diz Bourdieu (1997) é neste momento que o pesquisador empreende o "exercício espiritual" (p. 699) de "se colocar em seu lugar (do pesquisado) em pensamento", para dominar ou enfrentar, mas não anular, as assimetrias existentes e, assim, controlar as interferências que elas geram na interação e estabelecer "uma comunicação não violenta" (p. 695). Encontros e desencontros entre pessoas de diferentes mundos, cujo tempo para que se encontrem nem sempre é condizente ou está previsto no cronograma da pesquisa. Os caminhos e atalhos definidos para lidar com essas situações nem sempre são declarados e devidamente analisados como componentes intrínsecos ao campo da pesquisa e ao objeto de estudo.

De tudo o que pode acontecer nos bastidores de uma pesquisa, o que pode contribuir ou não para o bom andamento da mesma, só podemos falar com autoridade da nossa própria experiência e do modo como a traduzimos e introduzimos como ingrediente fundamental no processo de trabalho científico. É disto que trata este artigo. Procuramos refletir sobre como certas situações de embaraço, por nós vivenciadas, contribuíram, substancialmente, para a nossa formação científica, tanto para melhor nos situarmos no campo empírico, quanto para esclarecermos nossos objetos de estudo. Não se trata de fazer um manual, peça fundamental do que Becker (1999) chamou de "processo de industrialização das ciências sociais", já que eles prescrevem o fazer do cientista social sem levar em conta a singularidade dos seus objetos de trabalho. Pelo contrário, ainda inspirados em Becker (1986), e também em Mills (1975), refletimos sobre o "artesanato científico" cabível a certas situações que nos deparamos no campo empírico. Quando se trata de pesquisa 
qualitativa no campo social, os procedimentos essenciais não são determinados a priori, já que os procedimentos, a ordem e o momento de utilização são definidos conforme as necessidades para conhecer o objeto de estudo se apresentam.

Organizamos a reflexão em duas seções, ambas oriundas de experiências empíricas distintas e singulares vividas pelos autores, cada qual no seu campo de trabalho. Sendo assim, cada seção tem assinatura própria. A primeira - batismo de fogo - trata dos testes empreendidos pelos pesquisados para admitir os pesquisadores no campo empírico. A segunda - gravador desligado - trata das formas escolhidas pelos pesquisados para fazer parte da pesquisa. Em conjunto, as duas seções tratam da participação ativa e propositiva dos sujeitos no curso da pesquisa e do problema da preparação prática do cientista para "perceber e controlar no campo, na própria condução da entrevista, os efeitos da estrutura social na qual ela se realiza" (Bourdieu, 1997, p. 694). A este processo Bourdieu (1997) denominou reflexividade reflexa, conceito que diz respeito ao domínio teórico e prático que o pesquisador possui sobre as condições sociais das quais o sujeito social pesquisado é produto.

A ideia de publicar estas notas nasceu da experiência dos autores em uma disciplina de conteúdo metodológico oferecida no Programa de Pós-Graduação em Psicologia da UFSCar. A convivência com estudantes de graduação e pós-graduação nos colocou diante da angústia de termos que lidar com a distância que se coloca entre o que se deve fazer (o prescrito) e o que, realmente, é possível e necessário fazer (o real) para estabelecer relações de trabalho com sujeitos em determinados campos de pesquisa. Assim, mais do que ensinar o que, em teoria, já é sabido quanto aos pressupostos e técnicas de busca, processamento e análise de informações, o propósito desta disciplina tem sido o de, a partir de um conjunto sugestivo de leituras, discutir as dificuldades e os percalços, bem como as soluções criadas e encaminhadas para o desenvolvimento de pesquisas, especialmente no que se refere ao trabalho de campo - as soluções ad hoc, como diria Becker (1999) - que nem sempre são devidamente consideradas na seção Método das Dissertações e Teses.

\section{Batismo de fogo: uma forma de conhecer quem quer me conhecer ${ }^{3}$}

Engana-se quem imagina que só o pesquisador está preocupado em conhecer quando entra no campo da pesquisa. Os nossos interlocutores estão vivos e são pensantes, também têm curiosidades e necessidades de nos conhecer, o que é natural nas interações humanas e sociais. Como disse Gonzales Rey (2002) “o sujeito pesquisado é ativo no curso da pesquisa, ele não é simplesmente um reservatório de respostas, prontas a expressar-se diante da pergunta tecnicamente bem formulada" (p. 55).

Não se trata apenas da apresentação formal que ocorre quando declaramos os nossos vínculos institucionais, os nossos objetivos, a forma de trabalhar para atingi-los e onde esperamos chegar ao realizar o nosso trabalho. Há situações em que os nossos interlocutores anseiam saber mais do que isto, ou seja, até onde chega o nosso comprometimento ético e político com a realidade

por eles vivida. É o que chamamos de "teste para a aceitação de pesquisadores" ou "batismo de fogo". São estratégias criadas pelos pesquisados não somente para melhor conhecer quem deles se aproxima, mas, sobretudo, para testar a correspondência entre os seus ideais e práticas, a afinidade dos seus argumentos e hipóteses de pesquisa com as do grupo pesquisador e a sua tenacidade para permanecer no campo mesmo em condições adversas.

3 Elaborado por Rosemeire Aparecida Scopinho a partir da experiência empírica oriunda de Scopinho (1996). 
No final dos anos 1990, visitei algumas cooperativas de produção agropecuária localizadas em assentamentos rurais da região Sul e Sudeste do Brasil, organizadas e geridas por militantes do Movimento dos Trabalhadores Rurais Sem Terra (MST), atendendo a uma demanda do próprio Movimento que, para enfrentar a crise econômica e política que acometia seus empreendimentos, recorria aos especialistas acadêmicos em busca de explicações e possíveis soluções para os problemas enfrentados. Como psicóloga, coube a mim avaliar a "parte social" ou "os problemas de relações humanas" - assim referidos pelos demandantes da pesquisa. Aos outros pesquisadores coube analisar os problemas relacionados ao funcionamento econômico e produtivo.

O novo tema e campo de investigação exigiram de mim um esforço inicial de exploração, de reconhecimento da literatura, do território dos assentamentos e suas cooperativas. As visitas iniciais tinham o objetivo de conhecer a experiência organizativa de cooperação desenvolvida pelo MST e, ao mesmo tempo, reunir alguns subsídios para discutir os problemas existentes, suas causas e possíveis formas de enfrentamento. E ainda desenvolver, em médio prazo, um programa de pesquisa sobre o tema, que, na época, despontava dentro da esfera de interesse científico de diferentes áreas do conhecimento. O fato dos assentamentos estarem localizados em áreas rurais de difícil acesso contribuiu na escolha das estratégias metodológicas para atingir os objetivos. Diante das dificuldades relacionadas ao transporte, tive que lá me hospedar, o que contribuiu para o estreitamento de vínculos, para a realização de observações diretas, para a oportunidade de conviver nesse ambiente em diferentes momentos e ter longas conversas com os que me hospedavam. No entanto, apesar da boa receptividade, do excelente acolhimento e da generosidade dos assentados, que ofereceram o que de melhor tinham em casa, o meu trabalho somente teve início depois de algum tempo de permanência, ou seja, depois do tempo necessário que eles precisaram para me conhecer e me aceitar entre eles. A hospitalidade impecável não significava livre acesso aos saberes do grupo.

Isto não é novidade para quem trabalha na área de ciências humanas e sociais com métodos qualitativos. Desde o final do século XIX, as reflexões metodológicas da Filosofia e da Antropologia somadas às da Sociologia do século XX têm alertado para o fato dos costumes, normas sociais e regras de comportamento não terem significado fora do contexto em que foram produzidas e são reproduzidas, sendo assim, a estreita convivência com os "nativos" é um instrumento ímpar de pesquisa, que os achados mais significativos são obtidos por meio do diálogo e da negociação dos pontos de vistas do pesquisador e do pesquisado, entre outros pressupostos importantes da pesquisa qualitativa. O que aqui se quer apresentar como objeto de reflexão são as formas desenvolvidas pelo grupo "nativo" em questão para acelerar este processo de aproximação, em razão dos seus interesses e expectativas. Tais interesses e expectativas em relação à pesquisa, vindos da parte dos pesquisados, é fundamental para motivar a adesão e participação deles no processo. O que não se dá sem antes de se assegurarem de que os pesquisadores têm aderência política à sua causa, posto que os pesquisados estejam conscientes de que os pesquisadores são uma espécie de "mediadores externos" da relação que eles estabelecem com o Estado e os movimentos sociais, como diz Novaes (1994, p. 179), já que são portadores de capitais simbólicos, entre outros tipos de capitais, e que as suas avaliações a respeito da realidade têm a força de "verdade" posto que são "científicas".

Em um dos assentamentos visitados, a estratégia utilizada pelo grupo para me conhecer melhor - posição política e tipo de capital disponível - foi a do rodízio da oferta de hospedagem e de alimentação. Nos sete dias que ali permaneci, nunca dormi ou comi em uma mesma casa. Nessas diferentes situações de encontro, tive de responder às mesmas perguntas sobre como era o meu trabalho, a família, afiliações políticas, entre outras questões (corriqueiras ou não). O trabalho de fazer e desfazer malas todos os dias para, às vezes, andar as poucas passadas que separavam uma casa da outra, não compensou as ocasiões em que eu mais respondia do que perguntava. Porém, nas muitas outras oportunidades que pude voltar, a recompensa veio na forma 
de depoimentos precisos sobre a história da ocupação, sobre as estratégias econômicas e políticas empreendidas pelo grupo para ocupar e manter o território, revelações dos assentados sobre suas condições e projetos de vida, suas representações sociais sobre diferentes temas e problemas. Isto nos leva a pensar que, mesmo a pesquisa sendo de interesse do grupo, mesmo que as portas do campo empírico tenham sido abertas e nele eu tenha sido conduzida por pessoas significativas e de plena confiança, conquistar a confiança dos informantes "chaves" para pesquisa é um processo que ocorre no interior do campo, não possuindo fórmula, nem tempo estimado para acontecer. $\mathrm{O}$ tempo para a realização da pesquisa, institucionalmente regulado e não raramente escasso, pode até depor contra o pesquisador que escolhe adotar este tipo de abordagem.

Mas por que esta estratégia foi utilizada pelo grupo? O reconhecimento da posição do pesquisador e do tipo de capital que ele traria, fazia sentido naquele contexto quando se analisa o que acontecia na cooperativa. Eu soube que minha visita havia sido marcada naquela semana por conta da realização da assembleia geral ordinária que aconteceria ao final da mesma (a qual eu poderia participar como observadora). O que eu não sabia, e acabou ficando claro somente durante a assembleia, é que eu estava diante de dois grupos distintos de cooperados, isto é, a cooperativa "formal" abrigava esses dois grupos que, por terem interesses antagônicos, defendiam projetos organizativos diferentes. Em 1995, a partir da integração de três pequenos grupos de famílias originárias de diferentes localidades, a cooperativa foi formada no período de trinta dias, por meio da técnica de Laboratório Organizacional, criada por Clodomir Santos de Morais ${ }^{4}$. Entre os problemas enfrentados naquele momento estavam:

1. Falta de real envolvimento dos sócios no projeto de trabalho, que se dava com o desperdício de materiais e falta de disciplina (atrasos e realização de tarefas pela metade). O cotidiano, movido por um funcionamento improvisado e desarticulado, denunciava a falta de credibilidade do projeto da cooperativa por parte dos cooperados. De fato, principalmente os setores da horta e do almoxarifado exemplificavam a falta de cuidado com as matérias-primas, os insumos, as ferramentas e os produtos que ameaçavam a produtividade e até a segurança das pessoas, uma vez que naqueles locais se armazenavam e manuseavam ferramentas e produtos químicos de alta periculosidade;

2. Conflitos entre coordenadores e sócios em determinados setores de produção se manifestavam, por exemplo, em divergências no controle das horas trabalhadas. Devido a não utilização do relógio (por falta de costume), às vezes a marcação das horas trabalhadas era feita por aproximação. Os dirigentes da cooperativa estudavam uma forma para padronizar o apontamento das horas ou da implantação de um sistema de trabalho com pagamento por tarefa;

3. Conflitos em relação ao trabalho feminino, que representava, aproximadamente, $30 \%$ da força de trabalho ativa. Enquanto as mulheres se queixavam que a divisão do trabalho deveria considerar suas condições biológicas, ocupando-as com as tarefas mais leves, os homens se queixavam que as mesmas não cumpriam adequadamente o horário de trabalho. Em resposta, as mulheres alegavam não o fazer porque tinham que cuidar da

4 Segundo Marin, Zunica, Gonzalez, Puello, Londono \& Melo (1986) este método é "un sistema de procesos, contenidos y técnicas educativas que permiten la superación de niveles de conciencia, descubriendo y razonando para la acción constructora y transformadora del desarrollo comunitario a partir de la recreación social, donde se liga la practica-teoría-practica de manera sistemática y permanente." (p. 1) O método pode ser questionado pelo reducionismo com que aborda a teoria organizacional, ao supor que a consciência é um mero reflexo da prática de indivíduos "se plantea que existe una consciencia especifica en el productor artesanal, que es determinada o modelada por factores del entorno, tales como la estructura del mercado, el crédito, el estado del desarrollo tecnológico, la tenencia de la tierra y el modo de producción, entre otros." (p. 6). Ao pesquisar as cooperativas, constatei que o MST utilizou esta orientação desenvolvendo uma única oficina de formação dos cooperados, onde este processo educativo era intensivo e durava aproximadamente 20 dias, ocupando o tempo integral dos assentados, depois do qual se acreditava ter transformado as suas consciências no sentido da adesão dos trabalhadores assentados aos princípios do cooperativismo autogestionário. 
casa e dos filhos. Alguns entendiam que uma creche e um refeitório coletivo resolveria este problema;

4. Bloqueio do fluxo e interferência na comunicação, desde o encaminhamento de propostas, passando pelo processo de decisão até finalmente chegar à implantação das decisões tomadas. Para incentivar o companheirismo e evitar fofocas, os dirigentes da cooperativa procuravam acompanhar mais de perto o funcionamento dos setores produtivos, informar e realizar balanços críticos a cada 15 dias. O que não resolveu o problema. Além disso, muitas propostas se perderam porque não foram levadas adiante.

$\mathrm{Na}$ dinâmica da reunião esses e outros problemas se revelaram, apontando para a heterogeneidade de posições existente no grupo de associados, que depositava grande expectativa na assembleia como forma de resolvê-los. Ocorreu que o clima de tensão e de formalidade na condução da assembleia confirmou e até acentuou as diferenças de posição dos dois grupos de cooperados em relação à cooperativa, culminando na saída de 12 famílias um mês após sua realização.

Ficou claro que, diante da possibilidade de ter observadores na assembleia que, por sua vez, mais cedo ou mais tarde, revelariam suas impressões sobre o funcionamento da cooperativa, a disputa entre os grupos estendia-se ao ponto deles tentarem perceber essas impressões antes mesmo da sua realização, na esperança de poder contar com elas em situação de impasse no processo decisório. A estratégia definida para isto foi a de não deixar os pesquisadores convivendo com uma só família para evitar que se criassem laços que pudessem interferir no resultado da pesquisa. Obviamente, depois de muito visitar assentamentos rurais, fui percebendo outras questões que estão envolvidas no critério de escolha de famílias para hospedar visitantes, entre elas, a existência de quarto com cama disponível e o peso do custo da oferta de alimentação no orçamento familiar, que dependem mais da situação econômica dos assentados do que de qualquer outra razão. Neste caso, a questão fundamental era garantir a imparcialidade dos pesquisadores ou, pelo menos, que eles tivessem oportunidade de conhecer os argumentos divergentes, no caso de uma possível tomada de posição que privilegiasse um ou outro grupo que disputava o controle da cooperativa.

Minha experiência em outro assentamento rural foi diferente, mas igualmente marcante. $\mathrm{Na}$ época, o assentamento era considerado uma espécie de vitrine onde o MST procurava demonstrar a viabilidade da reforma agrária no Brasil e onde, segundo as concepções dos seus militantes, as famílias organizadas em cooperativa mantinham um padrão de vida considerado muito bom, especialmente em termos de habitação, alimentação, educação infantil, política de proteção ambiental e de proteção social aos trabalhadores assentados. Por conta disso e também por conta da beleza da paisagem serrana que circunda as agrovilas, o território era muito visitado e assediado por diferentes personagens: de simples curiosos a políticos, investigadores, jornalistas e turistas. Aos olhos dos anfitriões, entre os mais inoportunos estavam alguns turistas estrangeiros que, durante a passagem pela cooperativa, contrariavam as regras locais: circulavam usando roupas de banho pela agrovila e enrolados apenas em toalhas pelo interior das casas onde estavam hospedados, nadavam ou tomavam banho de sol sem parte da roupa (o conhecido topless), consumiam bebidas alcoólicas em locais considerados inapropriados, entre outros costumes considerados estranhos. Como o turismo não era somente uma fonte de renda, mas também uma estratégia para dar visibilidade à cooperativa e à luta pela reforma agrária, os cooperados decidiram utilizar um barracão (local onde já havia funcionado uma oficina de costura) para hospedar os turistas sem causar incômodos às famílias, forma encontrada para minimizar os inconvenientes.

Como visitante, me hospedei no barracão e fiz as refeições na casa do presidente da cooperativa. A beleza da paisagem chamou minha atenção desde a chegada, assim como a minha curiosidade foi despertada ao saber da existência de uma grande cachoeira no assentamento, que nem mesmo 
alguns habitantes do lugar conheciam porque não tinham coragem ou ânimo para chegar até lá, já que, apesar de ser muito bonita, era de difícil acesso. A informação aguçou ainda mais minha curiosidade e então eu insisti no passeio, recebendo o alerta do guia de que era proibido desistir. A experiência que tive durante o percurso é quase indescritível: desci uma ribanceira íngreme me arrastando pelo chão no terreno úmido e escorregadio, me agarrando às raízes das árvores de uma mata fechada. Chegando ao vale, somente eu e o guia (os demais desistiram) seguimos por dentro do rio, único caminho de passagem, nadando e caminhando sobre pedras escorregadias até chegar ao pé da cachoeira. Ali recebi os cumprimentos do guia, que mais tarde descobri ser um líder respeitado entre integrantes do MST, e uma espécie de "atestado de coragem e persistência", o que ajudou a abrir as portas do assentamento para a realização do trabalho de campo. Parece que, ao concluir a visita à cachoeira, respondi perguntas importantes que o grupo se fazia a meu respeito: "Você veio aqui para quê? Turismo? Mera curiosidade? Ou por estar envolvida, de fato, com os nossos problemas e contribuir como puder para solucioná-los?"

Como prever em estratégias metodológicas pré-definidas que, para conhecer esta cooperativa, insistir em conhecer uma cachoeira e não desistir no meio do caminho, mesmo diante das dificuldades, seria a chave para abrir suas portas? $O$ passeio levado a termo, mesmo sem relação com o planejamento metodológico da pesquisa propriamente dita, foi fundamental para o seu bom andamento e continuidade. Certamente que a interação poderia ter sido facilitada por outros meios, mas, neste contexto, o desafio de levar o passeio a termo foi inteligentemente utilizado pelo guia como forma de conhecer e testar os seus interlocutores. A convivência com o grupo naquela oportunidade e também em outras, me mostrou que, durante o passeio, tive que provar ser tão determinada e "valente" em meu trabalho, quanto os que conseguiram chegar até o assentamento o foram, e que, sobretudo, meus propósitos em relação ao grupo eram confiáveis. Valentia, coragem e confiabilidade eram valores considerados importantes naquele lugar. A cooperativa no momento passava por um processo de integração de dois grupos distintos: famílias de diferentes localidades que passaram pela experiência luta pela terra e da ocupação que, sob a orientação do MST, estavam dispostas a trabalhar organizadas em cooperativa junto de outras famílias que o INCRA (Instituto Nacional de Colonização e Reforma Agrária), assentou na área com base em critérios técnicos e eleitoreiros (grupo da cidade). Para o primeiro grupo, a experiência da ocupação foi difícil: saindo da região central de Santa Catarina, perambulou por várias cidades até chegar ao litoral, onde ocuparia uma área de preservação ambiental; finalmente, depois de cinco anos, se assentaram na fronteira Oeste do estado. A trajetória deste grupo foi de muita privação e de luta pela sobrevivência, mas também de muito aprendizado organizativo e político. Os que acompanharam passo a passo a "Conquista da Fronteira" - nome dado ao assentamento - expressavam um sentimento de cansaço misturado ao prazer de terem conquistado a terra e ao orgulho de terem superado a extrema pobreza através da luta social. Tais sentimentos foram os responsáveis por unificar e fortalecer os laços entre os que compartilhavam as memórias dos tempos passados sob a lona preta, do futuro incerto, do medo da fome, da polícia e dos políticos.

Nos primeiros anos de existência dos assentamentos de reforma agrária é muito comum o assédio por parte de pesquisadores e estudantes de diferentes áreas do conhecimento, técnicos governamentais e não governamentais, políticos, militantes de outros movimentos sociais nacionais e internacionais que, cada qual com seus motivos, desejam desde apenas conhecer as experiências de luta até contribuir com o processo organizativo sugerindo projetos ou, simplesmente, algum tipo de conhecimento que possa ser útil. Com este assentamento não foi diferente. Além da aproximação dos turistas e visitantes, muitos técnicos governamentais e não governamentais impuseram projetos produtivos que exigiram investimentos, mas não trouxeram resultados economicamente positivos, resultando no que os cooperados chamavam de "elefantes brancos", 
ou seja, estruturas e equipamentos de produção ociosos e abandonados. Nesta cooperativa, por exemplo, esse foi o caso da oficina de costura para fabricar calças jeans. Montada com a orientação de um visitante argentino, o empreendimento ruiu em pouco tempo por falta de demanda do produto no mercado regional.

Em resumo, as características culturais, as histórias particulares desses grupos e as suas desconfianças em relação aos de fora, os levaram a criar formas de verificação e de distinção entre os que chegavam, antes de se deixarem envolver nas propostas trazidas pelos visitantes.

\section{O gravador desligado: as diferentes formas de participação dos sujeitos na pesquisa $^{5}$}

Uma das experiências mais desconcertantes que vivi nesta minha incipiente carreira de pesquisador ocorreu em fevereiro de 2012 na cidade de Teotônio Vilela (Alagoas), onde eu me encontrava para realizar um conjunto de entrevistas com trabalhadores do corte de cana-deaçúcar. Estudando as condições de vida e trabalho desses sujeitos e o que a literatura especializada chamou de "condicionamentos de classe", eu estava interessado, portanto, em observar o modo de vida dessas pessoas e, mais do que isso, em entender os mecanismos por meio dos quais os filhos do cortador de cana tornam-se cortadores de cana ou assumem uma condição social semelhante a de seus pais e avós. Como eu já conhecia alguns canavieiros do município - devido ao fato de ter realizado uma pesquisa na mesma região entre os anos de 2009 e 2010 - decidi pedir-lhes que me apresentassem a outros trabalhadores e trabalhadoras, o que ocorreu sem muita dificuldade. Neste sentido, foi muito valiosa a contribuição de um cabo ${ }^{6}$ de turma o qual, além de me apresentar a um grupo de canavieiros em Teotônio Vilela, ainda tratou de "desarmar" os seus ânimos, dizendolhes que a minha pesquisa "nem era coisa do governo, nem da usina", mas o trabalho de um jovem pesquisador ligado a uma universidade, interessado em analisar as suas condições de existência.

A maioria das entrevistas foi realizada na casa das pessoas que se prontificaram a colaborar com o meu estudo. Antes mesmo de partir para o interior de Alagoas eu sabia que seria muito difícil, ou até mesmo impossível, conversar com os canavieiros em seus locais de trabalho pelos seguintes motivos: (1) as usinas dificultam ao máximo o acesso de pesquisadores ou outros profissionais "suspeitos" - como jornalistas ou advogados que não estejam acompanhados por alguém da empresa - aos trabalhadores durante o horário de trabalho; (2) como o salário no corte de cana é pago de acordo com a produção, fazer com que os canavieiros parem o trabalho para responder a um rol de perguntas é uma atitude, no mínimo, constrangedora. Sendo assim, passei a acertar os horários dos encontros conforme a disponibilidade dos que concordaram em me falar da sua vida e do seu trabalho nas usinas de açúcar e álcool. Percebi que os sábados e os domingos eram os melhores dias para as reuniões, mas como ainda era época de safra da cana (que acontece de setembro a março em Alagoas), e muitos trabalhadores seguiam o esquema de $5 \times 1^{7}$ imposto pelas usinas, algumas entrevistas foram realizadas em dias de semana durante a noite.

Ao conversar com os trabalhadores, soube que aos domingos os canavieiros provenientes de outras regiões do estado e que moravam nos alojamentos das usinas durante os meses da safra, vinham para a cidade com o intuito de se divertirem e também de "fazerem a feira". Nesse momento enxerguei a possibilidade de ampliar o quadro empírico da minha investigação, dado que além de entrevistar os trabalhadores ditos "locais" eu poderia ainda coletar informações sobre

5 Elaborado por Charles dos Santos a partir da experiência empírica oriunda de Santos (2013).

6 O cabo é o funcionário da usina responsável por arregimentar os canavieiros e organizá-los em turmas com, em média, 50 trabalhadores.

7 Esquema em que o canavieiro trabalha durante cinco dias consecutivos e tem um de folga, sucessivamente. 
aqueles identificados pela literatura como "safristas", "de fora" ou "sertanejos". Desse modo, nos domingos em que não havia nenhuma entrevista marcada passei a frequentar os espaços onde os ônibus das empresas deixavam e apanhavam os canavieiros que vinham espairecer e fazer compras em Teotônio Vilela.

Os primeiros contatos com esses trabalhadores me fizeram recordar de um conhecido estudo de Pierre Bourdieu que, ao analisar a relação dos camponeses do Sudoeste da França com os seus próprios corpos e também com as mulheres da região, afirma que a aparência é apreendida como símbolo da condição social e econômica dos indivíduos. Fato que também foi identificado no meu caso: os cortadores de cana eram facilmente reconhecidos na feira pelas roupas que vestiam, o jeito como caminhavam e até a disposição denunciadora do corpo. A hexis corporal como signo social (Bourdieu, 2006); o corpo como estrutura socialmente constituída e reveladora de pertencimentos (Butler, 2006).

Diante das "evidências silenciosas" de tais corpos, procurei me aproximar o mais discretamente possível, muitas vezes iniciando a conversa com um simples: "O senhor é cortador de cana?". As respostas a esta pergunta foram de um modesto "Sou sim, senhor" até outras mais complexas e emblemáticas, como: "Sou sim, senhor. É trabalho, é?", ou "Sou sim. Por quê? É por causa da greve?". ${ }^{8}$ O pesquisador - usando calça jeans, camisa social e tênis surrado, além da mochila trazida às costas e um pequeno caderno na mão - lembrava, aos olhos dos canavieiros, os assistentes sociais, advogados ou ainda funcionários do escritório da usina. Quando me aproximei de um grupo de trabalhadores, imagino que alguns tenham pensado "Se não é problema talvez seja oferta de trabalho".

Após a minha presença no local ser justificada, inclusive retomando o argumento de que a minha pesquisa "nem era coisa do governo, nem da usina", passei a conversar com sujeitos dos mais distintos lugares: o jovem de 21 anos que saiu de Piranhas (sertão alagoano) para cortar cana em Coruripe e que me confidenciou ser aquela "a primeira e a última vez" que trabalhava para a Usina Guaxuma'; o rapaz de Olho d'Água das Flores (também no sertão alagoano) que afirmou conhecer um grande número de canavieiros que recorrem ao uso do álcool e do crack para suportar as jornadas exaustivas de trabalho nos canaviais; e, finalmente, o sujeito que inspirou a reflexão sobre o embaraço a que fazemos menção no título deste ensaio, um canavieiro vilelense de 20 anos.

A conversa com Francisco ${ }^{10}$ ocorreu na calçada do ginásio de esportes de Teotônio Vilela, uma imponente construção situada entre um conjunto habitacional erguido recentemente pela prefeitura e um aglomerado de bares, restaurantes e pequenas lojas que já fazem parte do centro da cidade. A rua que fica defronte ao ginásio é, jocosamente, chamada pelos moradores locais de "rua dos cabarés", alcunha devida ao fato de alguns estabelecimentos servirem como pontos de prostituição, inclusive bastante frequentados por canavieiros em dias de folga.

As perguntas que fiz a ele giraram em torno de temas como o trabalho, o salário por produção, a relação com os colegas. Aos poucos as respostas me ajudaram a traçar um quadro mental do sujeito que estava à minha frente. Apesar da pouca idade, Francisco já havia adquirido uma grande experiência de vida: trabalhava desde criança, primeiro na roça dos pais e depois nas plantações de cana dos grandes proprietários ou usineiros da região; sua família sempre esteve

8 Nos dias que antecederam a entrevista, trabalhadores da Usina Guaxuma entraram em greve para reivindicar o pagamento imediato dos salários atrasados, melhores condições de trabalho e o fim do contrato safrista dado que nesta modalidade de contrato eles perdiam o direito ao seguro-desemprego, que garantia as condições mínimas para muitas famílias manterem-se no período da entressafra.

9 Usina pertencente ao deputado federal João Lyra (PSD-AL). Recentemente o Supremo Tribunal Federal (STF) recebeu do Ministério do Trabalho uma denúncia contra este usineiro, que passou a ser réu em ação penal, acusado de manter cerca de 50 cortadores de cana em condições de trabalho análogas às da escravidão no município de União dos Palmares/AL. A pena prevista para este crime é de dois a oito anos de prisão. Cf. "STF recebe denúncia por trabalho escravo contra deputado de AL" (Santos, D., 2012).

10 Nome fictício. A entrevista ocorreu na manhã do dia 5 de fevereiro de 2012, em Teotônio Vilela (AL). 
ligada à agricultura de subsistência ou, pelo menos, até o momento em que, desprovida de terra, vira-se obrigada a trabalhar no corte de cana; os seus pais cortaram cana, os seus tios e irmãos também. Cortar cana, para ele, foi como uma imposição: "Se não fosse isso seria o que?", ele perguntou a mim (e a si mesmo). A resposta a este questionamento veio no decorrer do nosso encontro: para Francisco, hoje, ou é a cana ou é alçar voo para o Centro-Sul do país onde, ele dizia, a vida é bem melhor.

Francisco revelou que passara um ano morando em uma cidade do Paraná. Lá trabalhou como repositor de mercadorias em um supermercado, ganhando por volta de um mil e duzentos reais ao mês e desfrutando do "prazer" de "ficar na sombra e no ar condicionado". É sabido que as condições de trabalho oferecidas nas grandes e pequenas redes de supermercado não são nada agradáveis; além das longas jornadas, que em alguns locais chegam a ultrapassar as 12, 13 ou 14 horas, há ainda os baixos salários e a constante exposição aos riscos de adoecimento, com destaque para a Lesão por Esforço Repetitivo (LER). Para o meu interlocutor, porém, frente ao caráter predatório e desumanizador do trabalho no corte de cana, trabalhar como repositor de mercadorias significava dar um grande salto rumo a uma condição de vida melhor. A "sombra" e o "ar condicionado" estavam em oposição ao sol causticante, ao calor insuportável e à fuligem tóxica, que são algumas das marcas do trabalho no canavial. De fato, quando em 2009 e 2010 eu perguntei aos cortadores de cana de Teotônio Vilela o que, realmente, eles gostariam de ser ou fazer, uma das principais respostas foi, exatamente, trabalhar em um supermercado. Menos pelo salário, lembro que me disseram, e mais pela possibilidade de se realizar um trabalho em local coberto e, minimamente, ventilado. É válido acrescentar que eles não acreditavam que a inserção em tal atividade fosse a solução definitiva para todos os reveses decorrentes da sua condição de trabalhadores canavieiros - afinal, os entrevistados eram dotados de potencial crítico -, mas por representar, como dá a entender Lopes (1978), um mal menor diante das condições precárias em que o trabalho rural-agrícola nas usinas se vê imerso.

Em seguida, perguntei-lhe por que voltou, por que se inseriu novamente no corte de cana. Sem hesitar, Francisco contou que estava apaixonado por uma jovem do seu povoado e que, devido à saudade que sentia dela, acabou antecipando o seu retorno a Alagoas - ele pretendia primeiro fazer um bom "pé de meia" no Paraná e só depois regressar a Teotônio Vilela. Seu novo plano consistia em juntar dinheiro cortando cana, casar e migrar, definitivamente, para o Sul do país com a esposa. Para ele estava claro que ficar significaria estar atrelado à monocultura da cana-de-açúcar e aos interesses nefastos dos usineiros e grandes fazendeiros da região "Aqui não dá para estudar, para crescer; o usineiro não deixa você estudar; se você quer estudar, como é o meu caso e o de muitos outros, você tem que ir para fora", sentenciou. Esta sua fala vai ao encontro da assertiva thompsoniana de que "a classe constitui-se no seu fazer-se" (Thompson, 2002, p. 10). A sua experiência e a experiência das pessoas próximas - a "experiência vivida" e a "experiência relatada", de que trata Benjamin (1987) - o ajudaram a perceber, a se fazer "consciente" de que os interesses dos ricos proprietários de usinas e de terras são opostos aos seus e daqueles que partilham da mesma condição material e cultural. Ter um trabalho decente, estudar, "crescer", são desejos que esbarram na ganância do usineiro, para quem o que importa é a capacidade do funcionário de despender energia e gerar lucro.

Este foi o contexto no qual se deu a minha relação com Francisco. Logo de início ele proibiu que eu usasse o gravador para registrar as informações. Tal atitude me pareceu bastante compreensível, afinal, como escreve Queiroz (1991), o gravador pode ser uma fonte de inibição para determinados informantes, e não raro, algumas pessoas titubeiam, balbuciam e/ou tornam-se extremamente lacônicas diante da possibilidade de terem a voz "aprisionada" no referido aparelho. Entretanto, como pude perceber no decorrer da nossa conversa, a recusa de Francisco não estava apenas ligada ao desconforto causado pelo simples uso do aparato técnico, mas sim às implicações que a gravação daquela entrevista poderia ter na sua vida e na de sua família. 
Por ter sido concedida em local público e num dia muito movimentado, a entrevista poderia colocar Francisco em situação ameaçadora, caso ele fosse visto por um cabo, gerente de campo ou até mesmo algum colega de trabalho disposto a denunciá-lo aos superiores. Em certo momento da conversa Francisco passou a olhar nervoso para um lado e para o outro e a me dizer que não tinha "mais nada para contar" e que "era só isso mesmo". A sua narrativa, ora ou outra, era entrecortada por uma dessas duas sentenças, o que me deixou um tanto embaraçado, pois vinha crescendo dentro de mim a certeza de que aquele era um dos melhores depoimentos que eu tinha colhido durante a pesquisa de campo. Embaraço do informante, portanto, que tinha medo de ser visto, denunciado, perseguido e, por fim, demitido; e embaraço do pesquisador, que tinha medo de perder um bom informante, de colocá-lo numa enrascada, de não conseguir outros informantes.

Baseio-me em Queiroz (1991) para dizer que a técnica de histórias de vida e depoimentos pessoais bem pode ser chamada de "técnica da liberdade", pois permite ao informante ter certa autonomia em relação ao pesquisador; passa a ser aquele que gerencia a escolha do que vai dizer, o seu ritmo, a concatenação dos assuntos e ainda, como no caso que gerou esta minha reflexão, que decide quando a entrevista deve terminar. Para Francisco estava claro que ele já tinha se arriscado demais ao despender alguns preciosos minutos de seu domingo conversando sobre temas difíceis e comprometedores em um lugar onde olhos poucos amistosos poderiam vê-lo. Diante da sua necessidade de findar a entrevista para tratar dos assuntos que o trouxeram à feira, só restou-me agradecer a preciosa colaboração e desejar-lhe sucesso em suas próximas empreitadas, entre as quais se casar e mudar de estado.

Desde aquele fevereiro venho pensando nos aspectos teóricos, metodológicos, éticos e políticos envolvidos neste meu encontro com Francisco, aspectos estes que, na prática, não estão dissociados e, por isto mesmo, o trabalho de campo não deve ser pensado como momento isolado de um estudo, mas como situação concomitante e instigadora da análise teórica e da conscientização política, do pesquisador e dos pesquisados.

A abordagem dos canavieiros na feira se constituiu em uma verdadeira faca de dois gumes, isto porque se, por um lado, eu pude conversar com trabalhadores de vários locais, por outro, me deparei com uma série de problemas, tais como: a necessidade do informante de cuidar dos afazeres que o trouxeram à cidade, o improviso do espaço em que ocorreram as entrevistas (sem salas, cadeiras ou mesa de apoio) e, principalmente, o receio do entrevistado de ser visto pelos patrões ou colegas de trabalho "alcaguetes".

A pesquisa qualitativa, como dá a entender Gonzalez Rey (2002), está calcada na vontade do pesquisador de conhecer aquilo que está para além da superfície de um objeto de estudo, garimpar informações que revelem com profundidade a visão de mundo dos sujeitos, a sua subjetividade e as representações construídas em torno das suas práticas e/ou da sua condição social. Sendo assim, ela "é valiosa não só pelo conhecimento que produz sobre o estudado, mas também pelas novas zonas de sentido que permite descobrir em relação ao objeto de estudo" (Gonzalez Rey, 2002, p. 73). Também para Queiroz (1991), as técnicas relacionadas à pesquisa qualitativa - quando bem utilizadas - permitem ao pesquisador conhecer um grupo ou uma sociedade a partir de seu interior. O receio de Francisco em prolongar a conversa estaria fundado na consciência da contribuição que ele sabia dar com o seu depoimento para o aclaramento da condição social vivida por ele e tantos outros trabalhadores brasileiros? A posição social de Francisco aos poucos foi ganhando vida em minha mente a partir dos relatos sobre temas que, em princípio, diziam respeito apenas à sua experiência particular. Por meio desta experiência singular eu soube, entre outras coisas, que a usina tentava controlar os canavieiros, dentro e fora do local de trabalho; que se no eito os trabalhadores deveriam demonstrar disciplina, produtividade e respeito aos colegas e chefes, fora dele, no espaço da reprodução, deveriam se atentar para a discrição (sobretudo no que concernia o funcionamento da usina) e à "boa conduta". 
Outro aspecto marcante da pesquisa qualitativa é que o pesquisador é, ele mesmo, o seu principal instrumento de trabalho. Garantir um diálogo ético é fundamental para o desenvolvimento do trabalho, dado que o pesquisador não é um manipulador de amostras, mas sujeito de uma relação dialógica que tem na outra ponta um homem ou mulher que pensa, deseja, critica, sente, sofre, ama, cuja finalidade é a construção do conhecimento (Gonzalez Rey, 2002; Queiroz, 1991). Ambos estão envolvidos em uma rede de relações sociais, agindo a partir do lugar que ocupam na mesma. Ao utilizar a técnica de histórias de vida e depoimentos pessoais, cedo ou tarde, forma-se a ideia das condições sociais que envolvem o discurso do sujeito e lhe dão sentido. Uma preocupação ética frente a isto, portanto, é resguardar o direito do informante de apenas falar o que, como e quando quiser; é garantir que as informações repassadas não serão utilizadas para colocá-lo em situações vexatórias, causar-lhe danos físicos e/ou morais ou privá-lo de direitos. A apreensão nos olhos de Francisco me mostrava, concretamente, os riscos que ele corria ao participar da pesquisa.

O que me leva a discutir os aspectos teóricos, éticos e políticos relacionados à minha empreitada empírica em Alagoas. Vários estudiosos têm apontado a precariedade do trabalho canavieiro, entre eles Plancherel, Queiroz\& Santos (2011), Scopinho (2003), Silva (1990, 1999) e Verçoza (2011), os quais mostram que a exploração-dominação ocorre tanto dentro, quanto fora do espaço laboral, do eito. Como sugere Bourdieu (2007), são pesquisas que procuram pensar o trabalho, mas também o trabalhador; o sujeito e a sua história, perspectivas de mundo e as condições de vida. Penso que, além de me ajudar a esclarecer algumas questões referentes aos "condicionamentos de classe" - tema central do meu estudo em 2012 -, o trabalho de campo que realizei em Teotônio Vilela me ajudou a pensar nos meandros dessa exploração-dominação que estende suas garras para além do local de trabalho. Neste sentido, o argumento deleuziano (Deleuze, 1992) de que as "sociedades de controle" estão substituindo as "sociedades disciplinares" parece explicar o que eu vi e senti durante minha conversa com Francisco. Não é apenas na fábrica, no hospital ou no presídio que o sujeito é visado e disciplinado por um sistema. Hoje ele carrega dentro de si os apelos, normas e códigos disciplinares das instituições a que está ligado. Conforme Deleuze (1992):

...nas sociedades de disciplina não se parava de recomeçar (da escola à caserna, da caserna à fábrica), enquanto nas sociedades de controle nunca se termina nada, a empresa, a formação, o serviço sendo os estados metaestáveis e coexistentes de uma mesma modulação, como que de um deformador universal (p. 221-222)

Ora, foi essa continuidade que me chamou a atenção enquanto eu tentava produzir o meu estudo. O cabo poderia não aparecer, os colegas talvez nem estivessem prestando atenção na conversa que ele mantinha comigo, mas, ainda assim Francisco se sentia constrangido, receoso de que essa tenebrosa organização capitalista chamada usina tivesse acesso às suas declarações "subversivas". Não se trata apenas de uma introjeção do controle externo circunscrita ao ambiente de trabalho (Silva, 1990); trata-se de um controle que se manifesta mais agudo e, portanto, mais nocivo. A usina está cada vez mais interessada na subjetividade do trabalhador e, já não bastando o controle exercido no local de trabalho, é preciso se fazer presente - como "empresa-alma", "empresa-gás" (Deleuze, 1992) - no ambiente doméstico, nas rodas de conversa, nos espaços de lazer e na feira.

As consequências políticas dessa ampliação no controle que pude perceber no momento da conversa com Francisco e outros canavieiros, coisas que nem mesmo um gravador ligado poderia registrar. Na continuação da conversa com o trabalhador que me perguntou se eu estava ali para tratar da greve, percebi que a usina tentava desmoralizar ao máximo aqueles que participavam 
de movimentos sociais, greves ou paralisações como forma de exigirem os seus direitos. Esses eram apontados como arruaceiros, baderneiros, preguiçosos, verdadeiros "nós-cegos ${ }^{11}$ ". O homem demonstrou enorme receio em ser confundido com um grevista, mesmo após eu ter dito que não estava ali para identificar os trabalhadores que aderiram à greve, mas para saber sobre as suas condições de vida e trabalho. Depois de alguns minutos, a conversa foi encerrada com um desconcertante "Deus me livre de fazer greve, meu filho!". A questão é: até onde vai o controle da usina? Existe resistência entre os trabalhadores? É preciso problematizar essas indagações sem precipitação, porém, é possível ver de antemão que há sim um contrapoder nas práticas dos canavieiros, sejam estas no eito, transmudadas em "resistência miúda" (Silva, 2008), sejam nas ações mais abertas e com maior potencial de mobilização como os bloqueios de estrada, greves e ocupações.

A experiência relatada, a despeito de sua particularidade, caminha ao encontro daquele exercício bourdieusiano de, pelo menos mentalmente, pôr-se no lugar do outro. Se bem que os sinais demonstrados pelo meu interlocutor - o constante menear da cabeça, os olhos de preocupação - já ajudaram a desvendar o "território social" em que a nossa interação ocorria. $\mathrm{O}$ discurso de Francisco sobre si e sobre o mundo a sua volta - o "discurso extraordinário", de que trata Bourdieu (1997) -, ao revelar as teias de opressão e dominação, também revela a capacidade de resistir, manifesta, por exemplo, na sua própria coragem para estar ali e falar.

Em suma, gravador desligado ou não, o que de fato importou na experiência relatada foi a qualidade da relação estabelecida, porque da entrevista não se aproveita apenas a fala do entrevistado, mas também o modo como ele fala, o lugar de onde ele fala, as condições físicas e emocionais em que a conversa se dá, os olhares, os gestos, entre outros elementos que, às vezes, são mais significativos para conhecer o objeto de estudo do que o próprio conteúdo da fala.

\section{Considerações finais}

As angustiantes perguntas de quem empreende trabalho de campo na pesquisa social de natureza qualitativa podem não ter sido respondidas com esta reflexão, mas esperamos que ela contribua para ampliar os nossos olhares sobre os nossos fazeres, hoje tão pressionados pelas exigências burocráticas de uma ciência que, pressionada pelas exigências produtivistas, busca, justamente, mais a certeza da resposta e menos o exercício da dúvida reflexiva. No entanto, as experiências relatadas contribuem para objetivar pressupostos importantes da abordagem qualitativa em ciências humanas e sociais, tais como o de que o sujeito é pensante, ativo e propositivo no curso da investigação, o das indissociáveis relações dialéticas entre sujeito e estrutura social, entre teoria e método. Contribuem ainda para reafirmar a necessidade de pensar o método não apenas como um pré-requisito para iniciar os trabalhos de campo, conjunto estático de procedimentos linearmente dispostos, mas como um conjunto de estratégias passíveis de revisão e adequação ao sujeito e à realidade que se quer conhecer. Na prática intelectual, essas contribuições podem implicar em maior clareza e objetividade no processo de definição e redefinição do objeto de estudo, das estratégias teórico-metodológicas para registrar, selecionar e analisar as informações obtidas no campo empírico que são essenciais para compreendê-lo. No campo empírico, elas podem evidenciar o real sentido do que Whitaker (2002), quando se refere à observação etnográfica, chama de "olhar poliocular", porque enxerga o sujeito pela ótica interdisciplinar e pode ser capaz de captar as suas determinações históricas, culturais e ideológicas e Bourdieu (1997), quando se refere à entrevista, chama de "escuta ativa e metódica" porque:

11 Expressão local usada para designar pessoas que causam transtornos, que criam problemas para os outros. 
...tão afastada da pura não-intervenção dirigida, quanto do dirigismo do questionário ... associa a disponibilidade total em relação à pessoa interrogada, a submissão à singularidade de sua história particular, que pode conduzir, por uma espécie de mimetismo mais ou menos controlado, a adotar sua linguagem e entrar em seus pontos de vista, em seus sentimentos, em seus pensamentos, com a construção metódica, forte, do conhecimento das condições objetivas, comuns a toda uma categoria. (p. 695)

Reafirmamos que o objeto desta reflexão não deve ser lido como as regras de um manual, mas como parte de uma experiência singular vivida por determinados pesquisadores nas relações estabelecidas com determinados sujeitos em determinados espaços e tempos sociais. Talvez isto não baste para ampliar saberes e orientar fazeres que se pretendam gerais e universais, mas esta não é mesmo a perspectiva epistemológica que adotamos e pretendemos fortalecer, quando no cotidiano do nosso trabalho nos dedicamos ao estudo dos processos psicossociais.

\section{Referências}

Becker, H. (1999). Métodos de pesquisa em Ciências Sociais (4a ed.). São Paulo, SP: Editora Hucitec.

Benjamin, W. (1987). Magia e técnica, arte e política: ensaios sobre literatura e história da cultura. (S. P. Rouanet, trad.). São Paulo, SP: Brasiliense.

Bourdieu, P. (1997). Compreender. In P. Bourdieu (Org.). A miséria do mundo (pp. 693-713). Petrópolis, RJ: Vozes.

Bourdieu, P. (2006). O camponês e seu corpo. Revista de Sociologia e Política, 26, 83-92.

Bourdieu, P. (2007). O poder simbólico (11a ed., F. Tomaz, trad.). Rio de Janeiro, RJ: Bertrand Brasil.

Butler, J. (2006). Vida precaria: el poder del duelo y la violência. Buenos Aires, Argentina: Paidós.

Deleuze, G. (1992). Post-scriptum sobre as sociedades de controle. In Conversações 1972-1990 (pp. 219-226). Rio de Janeiro, RJ: Editora 34.

Gonzalez Rey, F. (2002). Pesquisa qualitativa em psicologia: caminhos e desafios. São Paulo, SP: Thomson.

Lopes, J. S. L. (1978). O vapor do diabo: o trabalho dos operários do açúcar. Rio de Janeiro, RJ: Paz e Terra.

Marin, R. M., Zunica, J. M., Gonzalez, O. C., Puello, R. G., Londono, H. G., \& Melo, H. E. (1986). Laboratorio experimental de organización: una metodología para la capacitación en organización. Cartagena, Colômbia: SENA (Servicio Nacional de Aprendizage).

Mills, C. W. (1975). A Imaginação Sociológica (4a ed., W. Dutra, trad.). Rio de Janeiro, RJ: Zahar.

Novaes, R. R. (1994). Mediação no campo: entre a polissemia e a banalização. In L. S. Medeiros, M.V. Barbosa, M.P. Franco, N. Esterci, \& S. Leite (Orgs.), Assentamentos rurais: uma visão multidisciplinar (pp. 177-183). São Paulo: Unesp.

Plancherel, A. A., Queiroz, A. Santos, C. (2011). O "canguru” no universo canavieiro alagoano: saúde e precarização do trabalho na agroindústria açucareira. In A. A. Plancherel \& E. Bertoldo (Orgs.). Trabalho e Capitalismo Contemporâneo (pp. 59-80). Maceió, AL: Edufal.

Queiroz, M. I. P. de. (1991). Variações sobre a técnica de gravador no registro da informação viva. São Paulo, SP: T. A. Queiroz.

Santos, C. (2013). De pai para filho: um estudo da formação e produção antroponômica do trabalhador canavieiro alagoano. (Dissertação de mestrado). Universidade Federal de São Carlos, São Carlos.

Santos, D. (2012, 12 de agosto). STF recebe denúncia por trabalho escravo contra deputado de AL.

G1. Recuperado de http://g1.globo.com/politica/noticia/2012/03/stf-recebe-denuncia-por-trabalho-escravo-contradeputado-de0al.htmlScopinho, R. A. (1996). Processo Organizativo das Cooperativas de Produção Agropecuária - CPAs. São Paulo, Concrab-Confederação das Cooperativas de Reforma Agrária do Brasil Ltda. [digitado]

Scopinho, R. A. (2003). Vigiando a vigilância: política e prática de saúde e segurança no trabalho em tempos de qualidade total. São Paulo, SP: Fapesp, Annablume. 
Silva, M. A. de M. (1990). Como expulsar o camponês do proletário. Travessia: Revista do Migrante, 3(8), 5-11.

Silva, M. A. de M. (1999). Errantes do fim do século. São Paulo, SP: Unesp.

Silva, M. A. de M. (2008). Cortadores de cana e os (não) direitos. Travessia: Revista do Migrante, 21 (61), 26-36.

Spink, P. K. (1991). O resgate da parte. Revista de Administração, 26(2), 22-31.

Spink, P. K. (2003). Pesquisa de campo em psicologia Social: uma perspectiva pós-construcionista. Psicologia e Sociedade, $15(2), 18-42$.

Thompson, E. P. (2002). A formação da classe operária inglesa I: a árvore da liberdade (4a ed.). Rio de Janeiro RJ: Paz e Terra.

Verçoza, L. V. de. (2011). Labor nos "eitos gigantes”: a superexploração da força de trabalho nos canaviais de Alagoas. In A. A. Plancherel \& E. Bertoldo (Orgs.). Trabalho e Capitalismo Contemporâneo (pp. 81-106). Maceió, AL: Edufal. Whitaker, D. C. A. (2002). Sociologia rural: questões metodológicas emergentes. Presidente Venceslau, SP: Letras a Margem.

\section{Endereço para correspondência}

scopinho@ufscar.br, charlagoano@hotmail.com
Recebido em: 16/06/2014

Revisado em: 07/03/2015

Aprovado em: 23/03/2015 